\title{
BASIC CONDITIONS FOR IMPLEMENTATION OF AN EFFECTIVE STRATEGIC DECISION SUPPORT SYSTEM AT A HOSPITAL
}

\author{
Venelin Terziev ${ }^{1}$ and Stoyanka Petkova - Georgieva ${ }^{2}$ \\ ${ }^{1}$ Full Member of the Russian Academy of Natural History, Professor, Eng., \\ D.Sc. (National Security), D.Sc. (Economics), D.Sc. (Social Activities), Ph.D., Russian Academy of \\ Natural History, Moscow, Russia, Vasil Levski National Military University, Veliko Tarnovo, Bulgaria \\ University of Rousse, Rousse, Bulgaria, terziev@skmat.com \\ ${ }^{2}$ Associate Professor, Ph.D., University „Prof. d-r Assen Zlatarov” - Bourgas, Bulgaria, \\ s.p.petkova@gmail.com
}

\begin{abstract}
The strategic decision support system is an activity management system that can be adapted to an organization from the health care system. It is appropriate to be used by any hospital no matter of its capacity. The strategic decision support system enables to be estimated the financial results, the patients' needs for achieving successes in their health recovery, the operational activity and the hospital capacity. The purpose of this study is to represent the methodology for strategic decision support system design for estimating the hospitals' activity effectiveness.
\end{abstract}

Keywords: strategic decision support system, performance management system, fuzzy sets, hospitals.

\section{INTRODUCTION}

In the present study it is represented the first stage of the method for building a strategic decision supported system (SDSS) at a hospital - an example of an organization from the health care insurance system in the Bulgaria. This system is built according to the logic of Balanced Scorecard performance system (BSC). Also, there is represented the logic of building the hierarchical casual relations between the mission (vision), the goals, the strategies, the perspectives and the objectives. One of the contemporary approaches that helps to achieve the necessary balance between the strategic and operational aspects of a hospital management is the strategic decision support system (SDSS). The rapid competition at market conditions also impacts on the health care organizations (hospitals) to take care about the successful strategy realization and at the same time to take care about the activity realization effectiveness (Terziev, Petkova- Georgieva, 2019c, pp. 515-524; Terziev, Petkova- Georgieva, 2019d, pp. 525-533).

\section{THEORETICAL STUDY}

For the successful activity of any business organization there are two basic and at the same time balances demands - namely there must be done "the right things" and at the same time "the things must be done by the right way." This means, on the one hand to create good business-strategies, and on the other - to design an effective supply system for products and services that are necessary for the successful strategy realization (Petkova - Georgieva, 2018a, стр. 71 - 77; Petrova, Petrov 2018b, pp. 213-228). The Balanced Scorecard (BSC) is a Performance Management System that can be used in any business organization (including a hospital) no matter of its capacity to align vision and mission with customer requirements, 
manage and evaluate business strategy, monitor operation efficiency improvements and to build organization capacity (Khandwalla, 2010; Petrov 2019a, pp. 506-518). As a result, to be achieved it could guide the organizational mission and vision to the patients' demands and the daily work. Also, it could manage and estimate the business strategy and it could control the improvements of the operational effectiveness and, at last but not at least, it could design the organizational capacity and inform the whole medical stuff for the current activities.

Balanced Scorecard systems give us the ability to view three different dimensions of organizational performance: Results (financial and customer), Operations, and Capacity. In Balanced Scorecard vision, mission, and strategy at the corporate level are decomposed into different views, or perspectives, as seen through the eyes of business owners, customers and other stakeholders, managers and process owners, and employees. The owners of the hospital are represented by the Financial perspective; customers (including patients) and stakeholders are represented by the Customer perspective; managers and process owners by the Internal Business Processes perspective; and employees and infrastructure (Capacity) by the Learning and Growth perspective.

The balancing process of the scorecard system could be achieved through the four perspectives, through the decomposition of an organization's vision into business strategy and then into operative, and through the translation of strategy into the contribution with each member of the medical stuff from the hospital because all of them must be included at the strategies for successfully meeting the goals (Kaplan, and Atkinson 1998, Petrova, Petrov, 2019b, pp. 29-40).

The meaning of "strategy" in the current study is: all the business activities used that help the hospital to approach and to accomplish the mission and implement the future hospital's vision. The successful business organizations usually have more than one macro business strategy; typically, several common strategic themes or focused on areas that show up repeatedly across different businesses. At the next lower level of strategy (management or department strategy), the hospital managers develop the strategies for their business units that support overall organizational strategy and helps any proper business organization to reach its goals.

\subsection{Steps for Building a Balanced Scorecard System at a Hospital}

All the steps that are included in this study can be easily applied at any hospital. The supporting system for taking strategic decisions is based on the structure of The Balanced Scorecard System. Therefore, first we will represent in briefly the basic steps for building an organization's Balanced Scorecard (Milgrom, Roberts, 2016).

Step One is an Assessment of the organization's foundations, its core beliefs, market opportunities, competition, financial position, short- and long-term goals, and an understanding of what satisfies customers. An organization's strengths, weaknesses, opportunities, and threats are developed, discussed, and documented.

Step Two is the development of overall Business Strategy. In larger organizations, several overarching strategic themes are developed that contain specific business strategies. Strategy is a hypothesis of what we think will work and in order to be successful. The remaining steps provide the basis for testing whether our strategies are working, how efficiently they are being executed, and how effective they are in moving the organization forward toward its goals.

Step Three is a decomposition of business strategy into smaller components, called Objectives. Objectives are the components or activities that make up complete business strategies. Each theme decomposes into specific objectives that drive performance and can be measured.

In Step Four, a Strategic Map of the organization's overall business strategy is created. Using cause-effect linkages, the components (objectives) of strategy are connected and placed in appropriate scorecard perspective categories. The relationship among strategy components is used to identify the key performance drivers of each strategy that, taken together, chart the path to successful end outcomes as seen through the eyes of customers and business owners.

In Step Five, Performance Measures are developed to track both strategic and operational progress. To develop meaningful performance measures, one has to understand the desired outcomes and the processes that are used to produce outcomes. Desired outcomes are measured from the perspective of internal and external customers, and processes are measured from the perspective of the process owners and the activities needed to meet customer requirements. Relationships among the results we want to achieve and the processes needed to get the results must be fully understood. We use the strategic map developed in Step Four, and specifically the objectives, to develop meaningful performance measures for each objective. 
There are used three different models to get to the measures that matter most. Our goal is to identify the critical business drivers, measure them, and use the information to improve decision-making. The three models are:

The Logic Model - This model allows us to explore the relationship among four types of performance measures: inputs (what we use to produce value), processes (how we transform inputs into products and services), outputs (what we produce), and outcomes (what we accomplish). This model reinforces the logic of the strategic map by showing the relationship among the activities that produce good outcomes.

Process Flow - We apply the Flow-charting technique to build a better scorecard performance system, as flow charting processes helps identify the activities (and measures) that matter most to produce good outcomes.

Causal Analysis - Causal analysis identifies the causes and effects of good performance. We start with the result we want to achieve and then identify all the causes that contribute to the desired result. The causal model is most useful for identifying input and process measures that are leading indicators of future results.

In Step Six, new Initiatives are identified that need to be funded and implemented to ensure that our strategies are successful. Initiatives developed at the end of the scorecard building process are more strategic than if they are developed in the abstract.

A Balanced Scorecard System (BSC) provides a basis for executing good strategy well and managing change successfully. Building a Balanced Scorecard performance system using the approach described here will cause managers to think differently (more strategic) about their organization and their work. [6]

\subsection{Hierarchical Structure of the SDSS Performances by Goals, Strategies, Perspectives, Objectives}

The rapid competition between the organizations demands the process of taking strategic decisions to be supported by specialized instruments. Therefore, it is necessary a Strategic Decision Supported System (SDSS) to be build, which has to function as an additional module to BSC for a strategic management of the organization. A basic function of this system is to support the process of taking decisions when there are badly structured problems to be solved that cannot be influenced by routine methods. The level of achieving the strategic goals can be used as a quality criterion for taking decisions. Therefore, a basic task for SDSS is to provide a maximum expectation of the strategic initiative results impact and the taking of strategic decisions on the strategic goals and the whole organizations' vision (Keating, 1997).

To fulfil the assigned tasks SDSS has to respond to the next conditions: to be able to capture and report performance that are described by different dimensions, to allow higher level constants aggregating, to allow giving of values and level of compensation between the parameters.

When there is building of SDSS at a corporate level it is necessary to observe the conditions for a constant and calculate systematization, receptivity and transparency, maximum simplicity, quick adaptation to the changes in conditions and possibility of graphical deduce of the parameters, normalized on the dimensionless scale (Simons, 2017).

The structure designing of SDSS follows the hierarchical structure of BSC. Therefore, for every goal there must be developed a separate pyramid and hierarchical structure of performance.

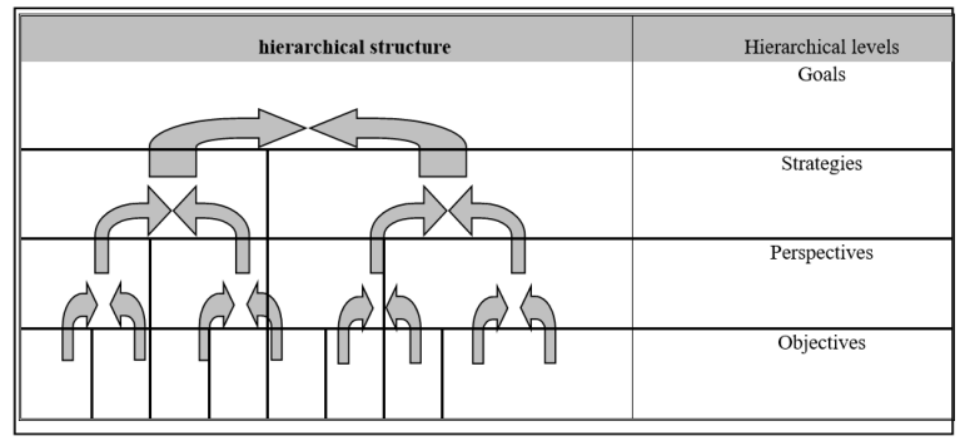

Fig. 1. Hierarchical structure of the SDSS performances by Goals, Strategies, perspectives, objectives Performance values can be determined only on the lowest base level in the hierarchical structure. The performance calculating from higher levels can be realized only with performances from lower levels by a calculating procedure (Simeonov, 2019e, pp. 2029- 2033; Simeonov, 2019f, pp. 9743-9745; Simeonov, 2019g, pp. 969-972; Simeonov, 2019h, pp. 987-988). The procedure for performance aggregating consists 
of next steps:

1. The objective performances are generalized into due perspective performances;

2. The perspective performances are aggregating to the due strategies;

3. The performance strategies are aggregating to the performance goals;

4. With the performance goals values can be described the meaning that reflects the organizations' vision.

A basic advantage of the offered procedure is that in contrast to all known methods it allows calculating of only one value, that unifies several functions.

After defining the weighting and the logical parameters of the SDSS performances they cannot be changed randomly any more. The strategic decision-maker can vary only with the goal factors depending on the specific situation (Christie, Joye, Watts, 1993).

The quick and accurate strategic problem solving is impossible without using proper mathematical methods for describing the system. A distinctive mark of this system is that together with the objective lows of this system an essential role is playing and the subjective concepts, the arguments and even the emotions of the people.

While analyzing an independent subsystem it must not be ignored its connections with the rest parts of the system. When there is a lack of any opportunities for a precise description of these interdependencies, practically there are used either any own concepts for these interdependencies or either the attempt of experts. For this activity it is important to mention that the information for the analyzed subsystem guarantees most often usually is described by conceptions that have insufficiently definite meaning from a mathematical point of view. Therefore, we use The Fuzzy set theory (FST) for describing the calculated interdependencies in SDSS.

In the base of FST lies the concept fuzzy set. It is used as a meaning for mathematical modeling of some difficult to determine concepts that are used by the people traying to describe their understandings for the real system, when are understanding their wills, goals and so on. The concept "fuzzy set" means that the elements composing any multitude and having a common characteristic can possess characteristics in different degree and hence they can belong to the due multitude at different degree. Therefore, in the theory for the fuzzy sets there are initiated the so-called membership functions (MF) that describe at what degree every element belongs to the fuzzy (Milgrom, Roberts, 2015; Nagar, 2014; Jensen, Meckling, 1992).

The FST is used in SDSS as everyone performance is defined by one basic value - standard. While comparing the values of the defined performance with its standard value results some kind of similarity that is reproduced by the belonging function. For this reason, to every performance used in the system is chosen and defined a MF.

It is essential to choose a similar MF. This will make easier the use of logical operators. In most of the cases it is chosen partial linear MF with a triangular, trapezium or Z-shaped form.

The MF can be determined directly by an expert's opinion or indirectly by statistical data or using a simulation model.

The traditional operators in FST "maximum" and "minimum" are not enough appropriate for aggregating of the performances in SDSS. For the purpose of the aggregating we suggest to be used the O'Grady's GAMA operator.

$$
\mu_{\theta}=\left(\prod_{i=1}^{m} \mu_{i}(x)^{\delta_{i}}\right)^{1-\gamma}\left(1-\prod_{i=1}^{m}\left(1-\mu_{i}(x)\right)^{\delta_{i}}\right)^{\gamma} \quad 0 \leq \mu \leq 1 \quad 0 \leq \delta_{i} \quad 0 \leq \gamma \leq 1
$$

The " $\gamma$ " performance measure describes the level of exchange, the " $m$ " performance measure indicates the number of performances that have to be aggregated in only one level and are represented with their membership grades, the " $\delta$ " performance measure describes the weighting factors of each performance measure (Barnett, Gallant, Hinich, Jungeilges, Kaplan, Jensen,1995, pp. 301-320; Barnett, Gallant, Hinich, Jungeilges, Kaplan, Jensen,1996, pp. 297-302).

The suggested model is a convex combination of algebraic product and an algebraic sum. In the binary logic they correspond to the logic "AND" operator - intersection, respectively "OR" operator - union. As a 
representative to the "AND" operator is $\left(\Pi \mu_{i}(x)\right)$, and as a representative to "OR" operator is the algebraic sum $\left(1-\Pi\left(1-\left(\Pi \mu_{i}(x)\right)\right.\right.$.

The performance measure " $\gamma$ " vary between 0 and 1. It indicates the level of performance measure mutual substitution that has to be aggregated. The value of " $\gamma$ " performance measure can be obtained only by an experience by calculating the next formula. The values of $\mu(\mu \mathrm{i}, \mu \theta)$ are as a result of an expert's opinion of the due specialists.

$$
\gamma=\frac{\log \mu_{\theta}-\log \prod \mu_{\mathrm{i}}}{\log \left(1-\prod\left(1-\mu_{\mathrm{i}}\right)\right)-\log \prod \mu_{\mathrm{i}}}
$$

The action of " $\gamma$ " performance measure much resembles the humanity decision making. The direct weighting assessment exceeds the capabilities of the humanity. Therefore, any significant method for an expert assessment must be used (Bouwens, Abernethy, 2000).

We use the Guilfords' method of "constant sums" that is a modification of Saatys' method. It is characterized with binary comparison of the performance measures as the experts' task is to divide 100 points according to their relative preference. At " $n$ " performance measure it comes matrix of preferences A ( $n$ $x \mathrm{n}$ ). The individual values aij indicate how many points have got the i performance measure in comparison with the j performance measure. After that we create the matrix $B$, which elements bij can be calculated by the next way:

bij $=$ aij / aji

The weighting of every performance measure comes out of the vector of the weighting factors that is a resolution of the above equation.

\section{$B . W=\lambda \max . W$}

Where $\lambda \max$ is the biggest eigenvalue of the $B$ matrix and $W$ is the due eigenvector.

While using the " $\gamma$ " performance measure the membership grade decreases with passing to every next aggregated level. Therefore, all the aggregated performance measures that have to be aggregated again must be standardized again in the interval $(0,1)$. For this reason, the next formula is used:

$$
\mu_{\text {normi }}(\mathrm{x})=\frac{\mu_{\mathrm{i}}(\mathrm{x})}{\max \left[\mu_{\mathrm{i}}(\mathrm{x})\right]}
$$

\section{INVESTIGATION RESULTS: TESTING THE MODEL OF "FUZZY SETS" AT BULGARIAN HOSPITALS}

The strategic decision support system is tested at 7 Bulgarian hospitals. For the purpose of the study there are conducted experiments among 87 hospital managers (48 male and 39 female) who work as medical directors at different levels - from the top to bottom of the hospital structures. The period of the tested results is for 4 years (2015-2018). The tested managers are divided by gender, management level at the hospitals and age group. The registered results are from tested managers as follows: 19 medical managers (8 male and 11 female) for the year 2015, 20 medical managers (14 male and 6 female) for the year of 2016, 27 medical managers (15 male and 12 female) for the year of 2017, 21 medical managers (11 male and 10 female) for the year of 2018.

Also, there is a second separation of the tested medical mangers in order to obtain better results: we divided them into 5 groups by their age and gender: till 30 years old $(25$ medical mangers -11 males and 14 females), between 31-40 years old (10 managers - 8 males and 2 females), between 41-50 years old (15 managers - 8 male $и 7$ female), between 51-60 years old (11 managers - 8 male $и$ female), more than 61 years old ( 7 medical managers - 2 males and 5 females).

Table 1 shows the results from the tested medical managers using the steps of the model "fuzzy sets" by estimating the impact of the three criteria - gender, management level and age. It is important to notice as a result that the three characteristics have very strong impact on the effective work of the strategic decision support system among the experimented 7 Bulgarian hospitals. 
Table 1. The results from testing the model "fuzzy sets" among 87 medical mangers (at different management level) from 7 Bulgarian hospitals.

\begin{tabular}{|c|c|c|c|c|c|c|c|c|}
\hline & male, & male, & male, & male, & female, & female, & female, & female, \\
2015 & 2016 & 2017 & 2018 & 2015 & 2016 & 2017 & 2018 \\
\hline male, 2015 & $\langle 1.00 ; 0.00\rangle$ & $\langle 0.48 ; 0.05\rangle$ & $\langle 0.48 ; 0.14\rangle$ & $\langle 0.71 ; 0.00\rangle$ & $\langle 0.52 ; 0.14\rangle$ & $\langle 0.67 ; 0.00\rangle$ & $\langle 0.76 ; 0.00\rangle$ & $\langle 0.81 ; 0.00\rangle$ \\
\hline male, 2016 & $\langle 0.48 ; 0.05\rangle$ & $\langle 1.00 ; 0.00\rangle$ & $\langle 0.48 ; 0.24\rangle$ & $\langle 0.57 ; 0.14\rangle$ & $\langle 0.52 ; 0.24\rangle$ & $\langle 0.38 ; 0.19\rangle$ & $\langle 0.47 ; 0.10\rangle$ & $\langle 0.43 ; 0.19\rangle$ \\
\hline male, 2017 & $\langle 0.48 ; 0.14\rangle$ & $\langle 0.47 ; 0.24\rangle$ & $\langle 1.00 ; 0.00\rangle$ & $\langle 0.38 ; 0.33\rangle$ & $\langle 0.62 ; 0.14\rangle$ & $\langle 0.52 ; 0.14\rangle$ & $\langle 0.67 ; 0.10\rangle$ & $\langle 0.38 ; 0.24\rangle$ \\
\hline male, 2018 & $\langle 0.71 ; 0.00\rangle$ & $\langle 0.57 ; 0.14\rangle$ & $\langle 0.38 ; 0.33\rangle$ & $\langle 1.00 ; 0.00\rangle$ & $\langle 0.52 ; 0.24\rangle$ & $\langle 0.62 ; 0.05\rangle$ & $\langle 0.57 ; 0.10\rangle$ & $\langle 0.81 ; 0.00\rangle$ \\
\hline female, 2015 & $\langle 0.52 ; 0.14\rangle$ & $\langle 0.52 ; 0.14\rangle$ & $\langle 0.62 ; 0.14\rangle$ & $\langle 0.52 ; 0.24\rangle$ & $\langle 1.00 ; 0.00\rangle$ & $\langle 0.57 ; 0.14\rangle$ & $\langle 0.71 ; 0.10\rangle$ & $\langle 0.43 ; 0.24\rangle$ \\
\hline female, 2016 & $\langle 0.67 ; 0.00\rangle$ & $\langle 0.38 ; 0.19\rangle$ & $\langle 0.52 ; 0.14\rangle$ & $\langle 0.62 ; 0.05\rangle$ & $\langle 0.57 ; 0.14\rangle$ & $\langle 1.00 ; 0.00\rangle$ & $\langle 0.81 ; 0.00\rangle$ & $\langle 0.76 ; 0.00\rangle$ \\
\hline female, 2017 & $\langle 0.76 ; 0.00\rangle$ & $\langle 0.48 ; 0.10\rangle$ & $\langle 0.67 ; 0.10\rangle$ & $\langle 0.57 ; .10\rangle$ & $\langle 0.71 ; 0.10\rangle$ & $\langle 0.81 ; 0.00\rangle$ & $\langle 1.00 ; 0.00\rangle$ & $\langle 0.62 ; 0.05\rangle$ \\
\hline female, 2018 & $\langle 0.81 ; 0.00\rangle$ & $\langle 0.43 ; 0.19\rangle$ & $\langle 0.38 ; 0.24\rangle$ & $\langle 0.81 ; 0.00\rangle$ & $\langle 0.43 ; 0.24\rangle$ & $\langle 0.76 ; 0.00\rangle$ & $\langle 0.62 ; 0.05\rangle$ & $\langle 1.00 ; 0.00\rangle$ \\
\hline
\end{tabular}

\section{CONCLUSIONS}

As a conclusion, the study leads to the opinion that the contemporary Bulgarian hospitals need to be both strategically and operationally flexible to survive and meet tomorrow's challenges. Doing the right things and doing things right is essential for the development of good business strategies and efficient operations to deliver better medical services required to implement the strategies. An approach that helps to achieve the required balance between strategy and operations is the Balanced Scorecard System. Nowadays, the health care organizations (hospitals) also must be successful both in strategic and operational aspect, so that they can survive and meet the future challenges. The next stage for developing SDSS includes the developing of a calculating model of the casual relations between the objectives in and between the perspectives.

\section{REFERENCE LIST}

Barnett, W.A., Gallant, R.A., Hinich, M.J., Jungeilges, A.J., Kaplan, D.T. and Jensen M.J., (1995).

"Robustness of Nonlinearity and Chaos Test to Measurement Error, Inference Method and Sample Size", Journal of Economic Behavior and Organization, 27, 301-320.

Barnett, W.A., Gallant, R.A., Hinich, M.J., Jungeilges, A.J., Kaplan, D.T. and Jensen M.J., (1996). "An Experimental Desing To Compare Tests of Nonlinearity and Chaos" In Barnett W.A Kirman,A.P. and Salmon M. (Editors) Journal of Econometrics 77, 297-302.

Bouwens, J. and Abernethy, M.A., (2000). The Consequences of Customization on Management Accounting System Design, Accounting, Organizations and Society, 25(3), 2000.

Christie, A.A., M.P. Joye, and R.L. Watts, (1993). Decentralization of the Firm: Theory and Evidence, WP, University of Rochester,1993.

Jensen, M.C. and Meckling, W.H., (1992). Specific and General Knowledge and Organizational Structure, in: Werin, L. and Wijkander, H. (Eds.) Contract Economics, Blackwell Publishers, Cambridge, 1992.

Kaplan, R.S. and A.A. Atkinson (1998), Advanced Management Accounting, Prentice Hall, Upper Saddle River, NJ, 3rd edition, 1998.

Keating, A.S., (1997). Determinants of Divisional Performance Evaluation Practices, Journal of Accounting and Economics, 24, 1997.

Khandwalla, P.N., (2010). The Effect of Different Types of Competition on the Use of Management Controls, 
Journal of Accounting Research, 10(2), 2010.

Milgrom, P. and Roberts J., (2016). Economics, Organization and Management, Prentice-Hall, Upper-Saddle River, NJ 2016.

Milgrom, P. and Roberts, J., (2015). Complementarities and Fit: Strategy, Structure and Organizational Change in Manufacturing, Journal of Accounting and Economics, 19, 2015.

Nagar, V., (2014) Interrelations Among a Firm's Delegation and Incentive Compensation Choices, WP, University of Michigan Business School, 2014.

Simons, R. (2017) Levels of Control, Accounting Control Systems and Business Strategy, Accounting, 4, 2017.

Petkova - Georgieva, St., (2018a). Basic Problems to Solve in Strategic Controlling Implementation, annual of "Prof. Dr. Assen Zlatarov", стр. 71 - 77, v. XLVII, book 2, Burgas, Bulgaria, 2018, ISSN 2603-3976.

Petrov Zhivo (2019a), Key Aspects and Analisys of European Defense Planning Processes, Proceedings of SOCIOINT 2019- 5th International Conference on Advances in Education and Social Sciences 21-23 October, 2019 - Istanbul, Turkey, pp. 506-518, ISBN 978-605-82433-7-8.

Petrova T., Petrov Zh., (2018b). Modelling the Distribution of Lasers in Biological Tissues, Int J Bioautomation, 22 (3), 213-228, doi: 10.7546/ijba.2018.22.3.213-228.

Petrova T., Petrov Zh., (2019b), Peculiarities in the Distribution of Temperature under the Influence of a Laser Beam in a Multilayered Medium, Int J Bioautomation, 23 (1), 29-40, doi: 10.7546/ijba.2019.23.1.29-40.

Terziev, V., Petkova- Georgieva, S. (2019c). The performance measurment system key indicators and the determinants impact on the level of decentralization using as an example a subdivisional unit from the Bulgarian social health and care experience. // Proceedings of SOCIOINT 2019-6th International Conference on Education, Social Sciences and Humanities 24-26 June 2019- Istanbul, Turkey, International Organization Center of Academic Research, Istanbul, Turkey, 2019, pp. 515-524, ISBN: 978-605-82433-6-1.

Terziev, V., Petkova- Georgieva, S. (2019d). A research study of nonlinearity experiencing in the rate of current account deficit to the Bulgarian health and care national product. // Proceedings of SOCIOINT 2019- 6th International Conference on Education, Social Sciences and Humanities 24-26 June 2019Istanbul, Turkey, International Organization Center of Academic Research, Istanbul, Turkey, 2019, pp. 525-533, ISBN: 978-605-82433-6-1.

Simeonov, Simeon. (2019e). Diagnose with "Mirizzi Syndrome". // 21 st International scientific conference: The teacher of the future, Budva, Montenegro, (07-09.06.2019), Institute of knowledge management Skopje, Macedonia, 31, 2019, 6, pp. 2029- 2033, ISSN 1857-923X (for e-version), ISSN 2545 - 4439 (for printed version).

Simeonov, Simeon. (2019f). VATS-Method of choice in traumatic hemothorax. // XXII International Scientific Conference: The power of knowledge (11-13.10.2019), Kavala, Greece, Institute of Knowledge Management, Skopje, 34, 2019, 4, pp. 9743-9745, ISSN 1857-923X (for e-version), ISSN 2545 - 4439 (for printed version).

Simeonov, Simeon. (2019g). Complications in severe acute cholangitis. // XXII International Scientific Conference: The power of knowledge (11-13.10.2019), Kavala, Greece, Institute of Knowledge Management, Skopje, 34, 2019, 4, pp. 969-972, ISSN 1857-923X (for e-version), ISSN 2545 - 4439 (for printed version).

Simeonov, Simeon. (2019h). Transanal endoscopic microsurgery (TEM) and NOTES. Pros and cons NOTES. // XXII International Scientific Conference: The power of knowledge (11-13.10.2019), Kavala, Greece, Institute of Knowledge Management, Skopje, 34, 2019, 4, pp. 987-988, ISSN 1857-923X (for e-version), ISSN 2545 - 4439 (for printed version). 